\title{
Manejo dos Pais Frente à Expressão de Raiva dos Filhos
}

\author{
Bruna Patrycia Waligura de Oliveira ${ }^{1}$ \\ Ana Karoline Gomes Gurtat ${ }^{1}$ \\ Aline Henriques Reis ${ }^{2}$ \\ ${ }^{1}$ Faculdade Assis Gurgacz, Cascavel, PR \\ ${ }^{2}$ Universidade Federal de Mato Grosso do Sul, Campo Grande, MS
}

\begin{abstract}
Resumo
O pai e a mãe têm uma importância fundamental no desenvolvimento psicossocial dos filhos, bem como na regulação das emoções. Na pesquisa objetivou-se investigar o manejo dos pais frente à expressão da emoção raiva dos filhos do sexo masculino e feminino. Participaram 26 casais tendo dois filhos de seis a doze anos. Para coleta dos dados, utilizou-se questionário de dados gerais, Critério de Classificação Econômica Brasil, entrevista estruturada e história-estímulo. Verificou-se que as estratégias mais utilizadas pelos pais e mães frente à raiva dos filhos foram reação centrada no problema e reação punitiva, respectivamente estratégias, adaptativa e desadaptativa. Tanto os pais quanto as mães tenderam a reagir com minimização maior com o filho e reagir com distração maior com a filha. Conclui-se que pais e mães utilizam-se das mesmas estratégias mediante à expressão de raiva dos filhos de ambos os sexos, porém, há diferenças de gênero quanto à prática parental.

Palavras-chave: raiva, reações parentais, crianças
\end{abstract}

\section{Management of Parents for their Children Expressing Anger}

\begin{abstract}
The father and the mother have a fundamental importance in the psychosocial development of children, as well as in the regulation of emotions. The objective of this research was to investigate the management of parents in the face of the expression of anger in male and female children. A total of 26 couples participated in the research, including couples that have two children from six to 12 years old. For data collection we used a general data questionnaire, the Brazilian Economic Classification Criteria, a structured interview, and a story-stimulus. We verified that the strategies most used by parents against their children's anger were problem-centered reactions and punitive reactions, respectively adaptive and maladaptive strategies. Both fathers and mothers tended to react with a greater minimization with the son and more distractedly with the daughter. It is concluded that fathers and mothers use the same strategies for both sexes against their children's anger expressions, but there are some gender differences in parental practice.

Keywords: anger, parental reactions, children
\end{abstract}

\section{Gestión de los Padres Para sus Hijos que Expresan la Ira}

\section{Resumen}

Los padres tienen una importancia fundamental en el desarrollo psicosocial de los hijos, así como en la regulación de las emociones. Se buscó investigar el manejo de los padres frente a la expresión de emoción de rabia de los hijos de ambos sexos. Participaron 26 parejas con dos hijos de seis a doce años. Para recolección de datos, se utilizó un cuestionario de datos generales, Criterio de Clasificación Económica Brasil, entrevista estructurada e historia-estímulo. Se verificó que las estrategias más utilizadas por los padres frente a la rabia de los hijos fueron; reacción centrada en el problema y reacción punitiva del problema; respectivamente, estrategias adaptativas y desadaptativas. Tanto la madre como el padre tienden a reaccionar con minimizacion mayor para el hijo y con más distracción con la hija. Conclusión: los padres utilizan las mismas estrategias mediante la expresión de rabia de los hijos, pero hay diferencias de género en cuanto a la práctica parental.

Palabras-clave: rabia, reacciones parentales, niños.

\section{Introdução}

As emoções decorrem de uma situação ambiental ou de recordações que eliciam alterações automáticas na fisiologia, na expressão facial e em gestos típicos referentes à emoção em curso (Cole, Martins, \& Dennis, 2004). Sendo que, possuem como características a duração curta, o início rápido e a ocorrência espontânea. $\mathrm{O}$ principal papel das emoções é mobilizar a pessoa para lidar rapidamente com outras pessoas e situações, independente do contexto interpessoal, mas considerando circunstâncias que foram adaptativas no passado evolutivo (Ekman, 1999).

Apesar da existência de variadas emoções, há algum consenso de que são cinco as emoções básicas: medo, tristeza, raiva, nojo e alegria (Ortony \& Turner, 1990; Widen \& Russell, 2008). As quais podem ser classificadas também como positivas e negativas, sendo a raiva, tema de estudo da presente pesquisa, considerada negativa. Esta é uma resposta natural do ser humano em que o corpo se prepara para lutar devido à presença de alguma ameaça, bem como uma emoção desconfortável 
que se manifesta em diferentes níveis que variam da irritação até a fúria. Uma pessoa que possui tendência a vivenciar a raiva pode expressá-la de modo agressivo, seja verbal ou fisicamente (Lipp, 2005).

A raiva organiza e regula os comportamentos interpessoais do indivíduo na sociedade, suas funções fisiológicas e processos psicológicos relacionados à autodefesa e tem a função de superar obstáculos a fim de alcançar objetivos. Dificuldades no gerenciamento da raiva podem piorar o funcionamento social e gerar problemas de comportamento (Lemerise \& Dodge, 2008).

$\mathrm{Na}$ infância, situações que eliciam raiva, na percepção das mães, envolvem brigas e discussões das crianças com irmãos, familiares e/ou amigos (Reis, Ferrari, \& Sperb, 2016). Por sua vez, receber apelido, ser xingado, empurrado, apanhar, ficar sem videogame, celular ou TV, não ganhar o que quer, promessas não cumpridas, ser acusado de algo que não fez, receber ordens ou repreensões do cuidador (Reis, 2014), bem como conflitos com colegas e problemas com professores (Cruvinel \& Boruchovitch, 2010) são eliciadores de raiva na percepção das crianças. Um estudo realizado por Cruvinel (2009) identificou eliciadores e frequência de estímulos que geram as emoções raiva, tristeza, medo e alegria na percepção de crianças de oito a 11 anos. As categorias encontradas por Cruvinel (2009) para raiva são definidas na Tabela 1, que será destacada nos resultados por conter exemplos de falas das mães e pais da presente pesquisa.

Apesar de a raiva ser uma emoção natural, sua expressão desadaptativa está associada a inúmeras doenças e prejuízos nas relações interpessoais. Deste modo, aprender a manejar a raiva, por meio da Regulação Emocional (RE) possibilita que as pessoas alcancem maior bem-estar e melhor funcionamento social (Lipp, 2005). Assim, RE pode ser entendida como um processo cognitivo que permite ao indivíduo a possibilidade de modificar intencionalmente determinadas emoções (Dias, Santos, \& Roazzi, 2006).

O aprendizado sobre como manejar as emoções se inicia na infância e os pais influenciam diretamente nas emoções e no comportamento dos filhos, assim, contribuem para o desenvolvimento de habilidades de RE das crianças por serem o seu sistema mais próximo de convívio. Portanto, justifica-se estudar a maneira como os pais reagem à expressão emocional dos filhos, pois eles serão o primeiro sistema, e um dos mais importantes no ensino da RE. Além disso, estratégias adequadas de RE em crianças correlacionaram-se a um relacionamento mais positivo com os professores, e apontam menor probabilidade de apresentar problemas de comportamento, sendo que habilidades de RE foram preditoras de sucesso acadêmico (Graziano, Reavis, Keane, \& Calkins, 2007).

As emoções podem ser interrompidas pela própria ação de controle da pessoa, (autorregulação) (Macedo \& Sperb, 2013), ou seja, quando o indivíduo realiza constantes avaliações do seu ambiente interno e externo a fim de controlar o comportamento de forma adequada (Diefenbach et al., 2008). Heterorregulação envolve o comportamento de outros diante da emoção expressada, podendo ocorrer a partir de comportamentos dos pais. Quando os pais atendem às necessidades da criança, a auxiliando-a na regulação de suas emoções, além de proporcionar-lhe um senso de segurança, esta tende a utilizar estratégias semelhantes àquelas empregadas pelos pais, o que permitirá o desenvolvimento de competências de RE (Rei, 2012).

A autorregulação emocional pode ser realizada a partir de estratégias adaptativas e desadaptativas. Estratégias adaptativas de RE envolvem: (1) solução de problemas, isto é, desenvolver um plano para lidar com o problema que se apresenta; (2) procurar apoio dos adultos, ou seja, buscar interferência direta de uma pessoa adulta considerada capaz de resolver o problema; (3) procurar apoio com pares, envolvendo busca por pessoas que possam oferecer suporte emocional ou com quem poderão conversar e desabafar; (4) ventilação da emoção, refere-se à expressão propriamente da emoção; (5) aceitação que envolve compreender eventos privados e consentir com a experiência emocional; (6) distração, é a direção do foco atencional para outros estímulos que não o eliciador da emoção; e (7) reavaliação cognitiva que abrange a percepção do indivíduo das situações e as emoções que sentem para mudar o significado da experiência negativa vivida. Por sua vez, as desadaptativas abrangem: (1) supressão, ou seja, ações que visam eliminar a experiência emocional; e (2) ruminação/preocupação, isto é, pensamentos recorrentes e intrusivos que mantêm a experiência emocional negativa (Eisenberg \& Spinrad, 2004; Macedo \& Sperb, 2013; Phillips, Henry, Hosie, \& Milne, 2006; Szasz, Szentagotai, \& Hofmann, 2011; Waters \& Thompson, 2014).

Szasz et al. (2011) estudaram os efeitos de diferentes estratégias de RE sobre a experiência e expressão de raiva em 97 estudantes de graduação, com idades entre 19 e 38 anos, que apresentavam um moderado nível de raiva-estado, sendo separados em três grupos experimentais conforme a estratégia de RE que lhes foi 
ensinada: (1) reavaliação cognitiva; (2) supressão; e (3) aceitação. Ao comparar os efeitos das três estratégias de RE sobre a raiva verificou-se que a reavaliação foi a mais eficaz em reduzir os níveis de raiva, quando comparada às estratégias de supressão e aceitação.

Outro estudo averiguou a regulação da raiva realizada por pré-adolescentes (idade média de 11,7 anos) que foram divididos em dois grupos: que têm o hábito de conversar sobre os acontecimentos de vida com a família (G1) e que não têm esse hábito (G2). Os dados foram coletados mediante a apresentação de duas histórias com conteúdo que provoca emoções e com final aberto. Concluiu-se que as estratégias mais utilizadas para lidar com a raiva para ambos os grupos, foram: buscar ajuda de adultos, agir de modo altruísta, ou seja, comportamentos aprovados socialmente, como a abnegação em favor de outros; e distrair-se. Porém, apenas os pré-adolescentes que conversavam sobre experiências que envolvem a raiva foram capazes de desenvolver habilidades de experienciar e lidar com a raiva de modo adaptativo (Macedo \& Sperb, 2013).

Palmeira, Gouveia, Dinis e Lourenço (2011) realizaram uma pesquisa para compreender a influência da expressividade emocional da família e esquemas emocionais ${ }^{1}$ das mães nas reações maternas perante a expressão de emoções negativas dos seus filhos. Os autores pretenderam verificar a existência de um efeito transgeracional das práticas parentais de socialização de emoções, com 172 mães com idades entre 29 e 52 anos, de crianças de oito a 12 anos de idade em Coimbra, sendo que $82 \%$ das mães da amostra eram casadas. Os resultados revelaram que as mães com crenças mais disfuncionais acerca das emoções tendiam a reagir mais negativamente perante a expressão de emoções negativas dos seus filhos. Aquelas que tiveram uma infância pautada pela ausência de suporte e validação emocional tenderam a apresentar com os filhos expressão emocional negativa. Os resultados revelam o efeito transgeracional, a vivência na infância num ambiente de hostilidade propicia a formação de crenças disfuncionais acerca a incontrolabilidade, não aceitação e invalidação das experiências emocionais das mães contribuindo para a adoção, na idade adulta, de reações negativas de não aceitação, desvalorização, crítica e punição perante a expressão de emoções negativas das suas crianças.

\footnotetext{
Esquemas emocionais são as crenças das pessoas sobre o significado, causas, implicações e estratégias comportamentais e interpessoais aplicadas a uma experiência emocional (Leahy, Tirch, \& Napolitano, 2013).
}

Alves e Cruz (2011) avaliaram 200 mães e 14 professoras de 200 crianças com idade média de 6,9 anos com o intuito de validar o instrumento que mensura reações parentais às emoções negativas. As respostas das mães revelaram que mães de meninos apresentaram mais frequentemente reações de punição e aborrecimento mediante às emoções negativas dos filhos, quando comparadas às mães de meninas. Mães com menos anos de escolaridade apresentaram mais reações de aborrecimento frente às emoções negativas dos filhos. Mães com níveis de escolaridade mais elevados apresentaram mais reações centradas no problema. De forma semelhante, Carmo e Alvarenga (2012) verificaram um efeito da escolaridade materna nas práticas educativas. Os autores encontraram que quanto menor a escolaridade da mãe maior a frequência do uso de punição física.

Chang, Schwartz, Dodge e McBride-Chang (2003) realizaram um estudo para verificar se pais e mães de 325 crianças chinesas com parentalidade severa (comportamento de punir e prejudicar a RE dos filhos) apresentam um efeito direto ou indireto sobre comportamentos agressivos dos filhos e os efeitos de interação entre pais e mães e o sexo das crianças. Os resultados indicaram que a mãe com parentalidade severa afeta mais as crianças na RE do que o pai, enquanto os resultados para o pai que exibe parentalidade severa revelam maior associação com agressão infantil. Pai com parentalidade severa afeta os filhos do sexo masculino mais do que as meninas, enquanto que não houve efeito diferencial em relação ao sexo com mães de parentalidade severa.

Sampaio e Vieira (2010) realizaram uma pesquisa com objetivo de investigar se existiam diferenças nas práticas educativas parentais considerando duas variáveis: o gênero e a ordem de nascimento dos filhos e da percepção da preferência parental a partir do ponto de vista dos filhos. A amostra contou com 322 adolescentes entre 13 e 17 anos. A pesquisa revelou que as meninas da amostra eram tratadas de modo diferente pelo pai, sofrendo mais com as práticas negativas, quando comparadas aos meninos. Além disso, as meninas apresentaram modelo de comportamento moral mais alto por parte das mães, e os meninos foram monitorados mais positivamente por parte do pai. Os autores cogitaram a hipótese de identificação sexual mãe - filha mulher e pai - filho homem, o que dizem poder facilitar a melhor interação das mães com suas filhas e dos pais com seus filhos. Constatou-se também que o gênero dos filhos interfere nos 
índices de estilo parental. As primogênitas apresentaram significativamente maiores riscos de sofrer com as práticas parentais negativas. Já no estudo de Canavarro e Pereira (2007), as meninas perceberam menos rejeição por parte do pai e da mãe e menos controle por parte do pai, além de maior suporte emocional por parte da mãe, comparando-se com os meninos.

Outro estudo buscou compreender o papel das estratégias de socialização dos pais e as suas relações com as crianças, RE e funcionamento psicológico. Participaram 60 famílias biparentais com 68 crianças (38 meninos e 30 meninas). Os resultados demonstraram que o pai fala mais do que a mãe sobre a raiva. Curiosamente, o pai conversa com seus filhos e filhas de forma semelhante e ambos os pais se sentem mais confortáveis falando de emoções conforme o sexo da criança. Crianças mais velhas conseguiam rotular os sentimentos mais facilmente que as mais novas (Crespo, 2013).

Em suma, verifica-se haver uma diferença entre os gêneros conforme a figura parental, ou seja, pais tendem a se identificar e manejar mais positivamente as emoções dos filhos do sexo masculino, enquanto as mães demonstram maior facilidade com as filhas (Canavarro \& Pereira, 2007). O gênero dos filhos também parece interferir nos índices de estilo parental, sendo que a idade das crianças e a escolaridade da mãe também podem interferir nas práticas parentais (Alves \& Cruz, 2011; Sampaio \& Vieira, 2010).

Parte-se da hipótese que a reação do pai e da mãe mediante à expressão de raiva do filho em relação à filha é diferente (Canavarro \& Pereira, 2007). Nesse sentido, o presente estudo tem como objetivo principal investigar o manejo dos pais em relação à expressão da emoção raiva dos filhos do sexo masculino e feminino. Além disso, almeja-se averiguar quais são os eliciadores da emoção raiva em crianças na percepção dos pais, investigar se há diferenças quanto à maneira com que os pais lidam com a expressão de raiva do filho comparado à filha, verificar também quais são as estratégias de regulação emocional que os pais usam no que discerne à expressão de raiva dos filhos de ambos os sexos, bem como verificar se há diferença na maneira como o pai lida com a expressão de raiva dos filhos, quando comparado à mãe.

\section{Método}

\section{Participantes}

Participaram da pesquisa 26 casais heterossexuais, casados ou em união estável. A idade da amostra total variou de 27 a $49(M=37,77, D P=5,46)$. A idade das mães variou de 27 a $45(M=35,92, D P=5,32)$ e dos pais de 29 a $49(M=39,62, D P=5,05)$. A média de escolaridade da amostra total foi de 13,55 anos de escolaridade, das mães de 13,88 e dos pais 13,21 anos de estudo. O tempo de união dos casais foi de 9 a 19 anos $(M=13,92, D P=3,23)$. A idade dos filhos variou de 6 a 12 anos $(M=9,12, D P=1,94)$ e das filhas de 6 a 12 anos $(M=8,50, D P=2,11)$. A renda familiar variou de $\mathrm{R} \$ 1.100,00$ a $\mathrm{R} \$ 50.000,00(M=3.848,90, D P$ $=6.976,27)$, com as classes socioeconômicas variando de A1 a C2, conforme o Critério de Classificação Econômica Brasil (CCEB) segundo a Associação Brasileira de Estudos em Pesquisa (ABEP, 2013). Os critérios de inclusão envolveram que o casal morasse na mesma residência, tivesse pelo menos dois filhos com idade de 6 a 12 anos, sendo um do sexo feminino e um do sexo masculino, sendo ambos filhos biológicos do casal.

\section{Instrumentos}

Foi utilizado um questionário de dados gerais e perguntas abertas: "O que costuma deixar seu filho com raiva? Com que frequência ele costuma sentir raiva? Conte uma situação em que seu filho sentiu raiva. $\mathrm{O}$ que você fez na ocasião? Nessa situação, quanto tempo durou a raiva de seu filho?", e a história-estímulo, utilizada no estudo de Ferrari et al. (manuscrito submetido para publicação): "Seus filhos estão assistindo TV e o (a) irmão(ã) menor quer brincar com o(a) irmão(ã) mais velho(a). Porém, o mais velho prefere assistir ao desenho que está passando. Então o(a) filho(a) mais novo(a) muda o canal da TV, faz birra e puxa a roupa do filho(a) mais velho(a). Este fica com muita raiva e começa a gritar com o(a) irmão(ã) para que ele pare de incomodar. Você que estava na cozinha ouve o barulho e vai até eles. O que acontece depois?".

O CCEB foi utilizado para levantamento de características domiciliares para classificação econômica. É feita então uma correspondência entre as faixas de pontuação do critério e categorias de classificação econômica, definidas por A1, A2, B1, B2, C1, C2, D e E (ABEP, 2013).

\section{Delineamento e Procedimentos}

Utilizou-se o método de estudo de caso coletivo (Ventura, 2007). Os primeiros participantes foram selecionados a partir da rede de contatos das pesquisadoras. Realizado o contato, explicou-se o objetivo da pesquisa e fez-se um convite para participação. Havendo o aceite em participar da pesquisa, 
agendava-se o dia e horário em que ambos os pais estivessem disponíveis para a entrevista.

As entrevistas foram realizadas na residência dos casais, pai e mãe concomitantemente em cômodos distintos da casa, cada um com uma das pesquisadoras. No momento das entrevistas não houve interferências sonoras e os filhos não estavam presentes. Foram realizados 43 contatos, porém apenas 26 casais aceitaram participar.

No dia agendado para a entrevista, as pesquisadoras (duas) compareceram ao local combinado, se apresentaram e explicaram brevemente sobre a pesquisa e seus aspectos éticos. Após o aceite da pesquisa solicitava-se a assinatura do Termo de Consentimento Livre e Esclarecido (TCLE) para participação na pesquisa e outro para gravação. O chefe da família (renda maior) preencheu o instrumento CCEB e o questionário de dados gerais. Na sequência, foram realizadas as cinco perguntas descritas seguidas pela leitura dada história-estímulo que versa sobre a emoção raiva. A partir disso, solicitou-se que o pai e a mãe relatassem o que ocorre depois de cada evento descrito. Este procedimento foi realizado duas vezes com cada cônjuge, sendo a primeira metade dos casos direcionada inicialmente ao filho, e a outra metade as perguntas referentes à filha.

Ao final, solicitou-se a cada casal entrevistado a indicação de outros casais com o mesmo perfil bem como seus contatos telefônicos. Cada entrevista teve duração aproximada de 30 minutos, sendo gravada e transcrita posteriormente. Todos os critérios dispostos na Resolução 466/12 foram cumpridos, sendo o número do parecer de aprovação do comitê de ética em pesquisa 797.299.

\section{Análise dos Dados}

Para análise dos dados, realizou-se análise de conteúdo quantitativa, identificando-se a respectiva categoria de respostas na fala dos participantes. A apreciação dos dados foi realizada individualmente por cada pesquisadora, conforme categorias propostas na literatura, procedendo-se, em seguida, a um levantamento de frequência. De modo a verificarem-se diferenças entre os gêneros, realizou-se análise com o teste qui-quadrado. Todas as análises foram realizadas com o programa estatístico Statiscal Package for de Social Sciences (SPSS).

Após a transcrição das entrevistas, duas juízas ${ }^{2}$ avaliaram individualmente as respostas dos pais e mães e,

Graduadas em Psicologia e treinadas pela professora orientadora. em caso de discordância, uma terceira juíza ${ }^{3}$ ponderava a dissonância e definia-se a categoria. As categorizações abordaram: (1) os eliciadores de raiva nos filhos; (2) a reação dos pais e mães na situação em que o(a) filho(a) sentiu raiva; e (3) e história-estímulo.

\section{Resultados}

\section{Eliciadores da Raiva}

De modo a investigar os fatores que, na percepção dos pais, desencadeiam raiva nos filhos, foram realizadas duas perguntas: "O que costuma deixar o seu filho com raiva" e "Conte uma situação em que ele ficou com raiva". Os pais poderiam elencar tantos motivos causadores da raiva quanto quisessem. Por esse motivo, a quantidade de respostas para a categoria "eliciadores da raiva" foi maior do que a quantidade de participantes. Em alguns casos, os pais relataram um motivo, por exemplo, quando briga com o irmão, porém, na situação eliciadora da raiva, citaram outra causa, por exemplo, quando os pais retiram algo que a criança quer. No entanto, essas duas perguntas foram consideradas conjuntamente quanto à análise dos dados referentes aos eliciadores da raiva.

Os eliciadores de raiva foram classificados considerando as categorias do estudo de Cruvinel (2009). Destaca-se que Cruvinel (2009) propôs duas categorias distintas intituladas: Proibição e Frustração, e nesta pesquisa optou-se por unir ambas, pois se entende que a proibição, em geral, está associada ao desencadeamento de frustração. A categoria Conflitos entre os pares/ irmãos foi proveniente deste estudo, e inclui comportamentos de outras crianças, sejam irmãos ou pares, que incomodam a criança, mas que não se configuram em comportamento agressivo, levando a um estado de raiva. A Tabela 1 apresenta a definição das categorias eliciadoras de raiva, baseado em Cruvinel (2009) e derivadas da presente pesquisa, bem como exemplos de falas de pais e mães desta amostra que compuseram cada categoria. $\mathrm{O}$ cálculo de concordância foi de $84,67 \%$, após a categorização final realizada pelas pesquisadoras totalizando-se 174 ocorrências de respostas para ambos os pais (Tabela 2).

Verifica-se que pais e mães compreendem que os fatores que geram raiva tanto no filho quanto na filha envolvem frustração, seguido por conflitos entre pares/irmãos. Salienta-se a dificuldade dos pais,

\footnotetext{
3 Doutora em Psicologia com ampla experiência em atendimento
} clínico infantil e orientação a pais. 
Tabela 1

Definição das Categorias de Raiva (Baseadas em Cruvinel, 2009) com Exemplos da Amostra desta Pesquisa

\begin{tabular}{ll}
\hline \multicolumn{1}{c}{ Categoria } & \multicolumn{1}{c}{ Definição } \\
\hline Não sei & $\begin{array}{l}\text { Quando os pais não sabem os motivos que levam os filhos a sentirem raiva. } \\
\text { Exemplos da presente amostra: "não vejo ela com raiva [...] às vezes a gente passa } \\
\text { batido e não lembra" (P21) ; "não lembro" (P20). }\end{array}$ \\
Agressão física/verbal & $\begin{array}{l}\text { Respostas relacionadas a comportamento destrutivo, agressivo e violento dirigido } \\
\text { à criança. Exemplos da presente amostra: Alguém brigar com ele; tirar sarro dele. } \\
\text { "quando ela cai e alguém da risada" (M25). }\end{array}$
\end{tabular}

Falta de suporte afetivo-social Sensação de pouca atenção e afetividade de pessoas próximas à criança, como por exemplo, pais, irmãos, amigos e professores, bem como medo de ser abandonado ou de ficar sozinho. Exemplos da presente amostra: algo que a gente não faça; não dar atenção; não cumprir combinados. "Quando ela se sente preterida ou se acha menos, que a gente da mais atenção pra um do que pro outro" (P8); "ela tava do meu lado e a gente levantou pra comungar e o J. veio e trocou de lado com ela e ai quando eu sentei do lado dele, que ele abraçou meu braço ela falou 'você falou que ele não podia trocar' mas eu não lembro que eu falei que ele não podia trocar de lado" (M10).

Acontecimentos ruins

Ambiente escolar

Proibição/Frustração

Conflito entre pares/irmãos
Notícias, pensamentos e eventos negativos gerais que ocorrem no cotidiano da criança. Exemplos da presente amostra: menstruação vazar; cachorra destruir o boné. "acontece alguma coisa na escola, que assim a menstruação vaza" (sic) (P5); "[...] ele acabou deixando o boné lá em cima, lá fora, e a cachorra pego e estraçalho com o boné” (M8).

Acontecimentos pessoais relacionados à escola, como ter comportamento inadequado neste ambiente ou insucesso acadêmico. Exemplos da presente amostra: falta de respeito dos professores em sala de aula; professora criticar o odor da sala."a falta de respeito com que os professores estão agindo na sala de aula[...] a professora de ciências criticou o odor da sala né, e falou dos meninos né, e falou que os meninos já nascem cheirando chulé” (M15).

Referem-se a respostas em que a raiva é gerada quando as coisas não acontecem da maneira como a criança gostaria, bem como à impossibilidade de a criança realizar algo em função de regras impostas por um adulto. Expectativa quanto a um desfecho que não foi atingido e ainda situações em que os pais proíbem a criança de fazer alguma coisa. Exemplos da presente amostra: ser contrariado; proibir a criança de fazer aquilo que ela quer. "quando tira algo que ele quer muito" (M1); "não fazer o que ele realmente gosta, o que realmente ele quer naquele momento" (P2); sempre que ela é contrariada por qualquer coisa"(M11).

Inclui comportamentos de outras crianças, sejam irmãos ou pares, que incomodam a criança, mas que não se configuram em comportamento agressivo, levando a um estado de raiva. Exemplos da presente amostra: desentendimentos por televisão e outros eletrônicos; a presença ou existência do par/irmão. "nas questões das disputas entre eles (irmãos)" (M1); "quando um irmãozinho provoca ela por algum motivo" (P14). 
Tabela 2

Número Absoluto e Porcentagem quanto às Ocorrências e Quantidade de Pais para as Categorias Eliciadores de Raiva, conforme o Sexo do Filho

\begin{tabular}{|c|c|c|c|c|c|c|c|}
\hline \multirow{2}{*}{$\begin{array}{l}\text { Eliciadores de } \\
\text { raiva }\end{array}$} & \multicolumn{2}{|c|}{$\mathrm{N}^{o}$ de pais que falaram ${ }^{1}$} & \multicolumn{2}{|c|}{$\mathrm{N}^{\mathrm{o}}$ de mães que falaram ${ }^{1}$} & \multirow{2}{*}{$\begin{array}{c}\text { Total de } \\
\text { ocorrência } \\
\text { pais }^{2}\end{array}$} & \multirow{2}{*}{$\begin{array}{l}\text { Total de } \\
\text { ocorrência } \\
\text { mães }^{2}\end{array}$} & \multirow{2}{*}{$\begin{array}{c}\chi^{2}(p)[\text { pais x } \\
\text { mães }]^{3}\end{array}$} \\
\hline & Filho & Filha & Filho & Filha & & & \\
\hline Não sei & $2(7,69 \%)$ & $8(30,76 \%)$ & $1(3,84 \%)$ & $2(7,69 \%)$ & $10(11,49 \%)$ & $3(3,37 \%)$ & $4,31(0,038)$ \\
\hline $\begin{array}{l}\text { Agressão verbal/ } \\
\text { física }\end{array}$ & $5(19,23 \%)$ & $2(7,69 \%)$ & $5(19,23 \%)$ & $2(7,69 \%)$ & $7(7,86 \%)$ & $7(7,86 \%)$ & $0,00(1,000)$ \\
\hline $\begin{array}{l}\text { Conflitos entre } \\
\text { pares/irmãos }\end{array}$ & $8(30,76 \%)$ & $13(50 \%)$ & $12(46,15 \%)$ & $12(46,15 \%)$ & $21(24,13 \%)$ & $24(26,96 \%)$ & $0,35(0,553)$ \\
\hline $\begin{array}{l}\text { Falta de suporte } \\
\text { afetivo-social }\end{array}$ & $1(3,84 \%)$ & $3(11,54 \%)$ & $0(0 \%)$ & $4(15,38 \%)$ & $4(4,53)$ & $4(4,53 \%)$ & $0,00(1,000)$ \\
\hline $\begin{array}{l}\text { Acontecimentos } \\
\text { ruins }\end{array}$ & $0(0 \%)$ & $1(3,84 \%)$ & $1(3,84 \%)$ & $0(0 \%)$ & $1(1,14 \%)$ & $1(1,12 \%)$ & $0,00(1,000)$ \\
\hline Ambiente escolar & $0(0 \%)$ & $1(3,84 \%)$ & $1(3,84 \%)$ & $1(3,84 \%)$ & $1(1,14 \%)$ & $2(2,24 \%)$ & $0,34(0,558)$ \\
\hline Frustração & $24(92,30 \%)$ & $19(73,07 \%)$ & $23(88,46 \%)$ & $23(88,46 \%)$ & $43(49,42 \%)$ & $46(51,68 \%)$ & $0,70(0,402)$ \\
\hline Total & 40 & 47 & 43 & 44 & 87 & 87 & \\
\hline
\end{tabular}

Nota. 1) Cada pai pode ter apresentado respostas classificadas em mais de uma categoria; 2) Cada pai pode ter apresentado mais de uma resposta classificada na mesma categoria ao longo da entrevista; 3) Células em negrito indicam testes qui-quadrado que demonstraram diferenças estatisticamente significativas $(p \leq 0,05)$ entre pais e mãe.

quando comparados às mães, em identificar a raiva nas filhas $\left(\chi^{2}=4,45 ; p=0,035\right)$, sendo que $30,76 \%$ dos pais relataram não saber que eventos fazem as filhas sentirem esta emoção.

\section{Reações Parentais Frente à Raiva}

As respostas dos pais frente às perguntas: "Conte uma situação em que seu filho sentiu raiva." e "O que você fez nessa situação?" e à história-estímulo foram classificadas conforme categorias de reação parental frente à raiva: distração, reação centrada no problema, validação das emoções, reação punitiva, reação de minimização (Eisenberg et al., 1996; Cassano et al., 2007; Shields et al., 2001) e reação perturbada (Melo, 2005). A Tabela 3 apresenta as categorias e definição quanto à reação parental em relação à raiva, e os exemplos na presente amostra para cada categoria.

Ressalta-se que na mesma resposta pai/mãe poderiam listar mais de uma reação, por exemplo: "pedi pra ele devolver, pedi pra cada um ir para o seu quarto, e que devolva a calculadora pra ela. Porque independe se ela tava certa em usar ou não, não é ele que tem que ir lá e ter essa atitude, daí apaziguo" (M8), por esse motivo, o total de ocorrências pode ser diferente do número total da amostra, sendo as estratégias utilizadas nesse caso, centrada no problema e reação punitiva. O cálculo de concordância foi de $71,11 \%$ realizado pelas juízas e após a categorização final totalizaram-se 303 ocorrências para ambos os pais (Tabela 4). Ressalta-se que as 303 ocorrências são em relação às reações parentais para a situação específica (135) mais a soma das reações parentais da história estímulo (168).

Observa-se que a estratégia mais utilizada pelo pai e pela mãe frente à expressão de raiva dos filhos de ambos os sexos é a reação centrada no problema, seguida por reação punitiva e reação de minimização. Verificou-se que não houve diferença estatisticamente significativa, comparando-se o total de respostas de ambos os pais para filhos e filhas.

Todavia, ao se verificar diferença entre as estratégias de RE empregadas pelos pais em relação ao filho do sexo masculino e feminino, constatou-se que ambos os pais tendem a usar a estratégia de distração mais frequentemente para a filha: $23,07 \%$ dos pais $\left(\chi^{2}\right.$ $=6,78 ; p=0,09)$ e $34,61 \%$ das mães $\left(\chi^{2}=5,65 ; p=\right.$ $0,017)$. Observa-se que apenas uma mãe utilizou-se de validação das emoções, ainda que de forma rudimentar, como forma de prática parental. 34,61\% dos pais e mães utilizaram-se mais da reação de minimização 
Tabela 3

Reações Parentais frente à Expressão de Raiva dos Filhos

\begin{tabular}{|c|c|}
\hline CATEGORIA & DEFINIÇÃO \\
\hline Distração & $\begin{array}{l}\text { Ações de pais e mães que diminuam a intensidade da emoção da criança colocando } \\
\text { a atenção da mesma em outro evento que a faça esquecer-se da situação que ativou } \\
\text { aquela emoção perturbadora (Eisenberg et al., 1996; Cassano et al., 2007; Shields et } \\
\text { al., 2001). Exemplos desta amostra: mandei fazer outra coisa; falo pra ela pensar/ } \\
\text { acalmar. "eu já chamo ela, vem aqui vamos arrumar o teu quarto agora, aí pra fazer } \\
\text { com que vá passando e de repente passa" (M16); "pego brinco com ela e passou" } \\
\text { (P23). }\end{array}$ \\
\hline $\begin{array}{l}\text { Reação Centrada no } \\
\text { Problema }\end{array}$ & $\begin{array}{l}\text { Conversar sobre a situação tentando resolver o problema instalado ou revendo o } \\
\text { ocorrido (Eisenberg et al., 1996; Cassano et al., 2007; Shields et al., 2001). Exemplos } \\
\text { desta amostra: aconselhar; explicar; conversar. "Eu respeito à individualidade dele, eu } \\
\text { converso com os pequenos, 'agora não, vocês vão ficar aqui na sala e o F. vai ficar no } \\
\text { quarto dele' então eu converso e às vezes funciona e às vezes não" (M11); “depende } \\
\text { a situação, eu acho que cada situação você vai agir de uma forma tá, o que mais faz é } \\
\text { conversar" (P21). }\end{array}$ \\
\hline Validação das emoções & $\begin{array}{l}\text { Identificar a emoção expressa pela criança e encorajá-la a nomear e debater a } \\
\text { experiência emocional (Eisenberget al., 1996; Cassano et al., 2007; Shields et al., } \\
\text { 2001). Exemplos desta amostra: "eu vou conversar com ela, o porquê ela está desse } \\
\text { jeito" (M21). }\end{array}$ \\
\hline Reação Punitiva & $\begin{array}{l}\text { Punição ou restrição da expressão emocional da criança por parte dos pais (Eisenberg } \\
\text { et al., 1996; Cassano et al., 2007; Shields et al., 2001). Exemplos desta amostra: deixar } \\
\text { sem o objeto; obrigar a fazer atividades que não quer; “[...] Se for preciso até dar uns } \\
\text { puxão de orelha, uns tapinha” (P20); "Eu fiz ele lava" (M9). }\end{array}$ \\
\hline Reação de Minimização & $\begin{array}{l}\text { Comportamentos que desvalorizam a importância da reação da criança, da emoção } \\
\text { expressa ou do problema que a desencadeou (Eisenberget al., 1996; Cassano et al., } \\
\text { 2007; Shields et al., 2001). Exemplos desta amostra: falar que não era nada; não } \\
\text { fazer nada diante da situação; "Não fiz nada, só fiquei quieta, e não fiquei abraçando } \\
\text { segurando ele" (M10); "Eu falei pra ele não liga né [...]" (M6). }\end{array}$ \\
\hline Reação Perturbada & $\begin{array}{l}\text { Os próprios pais experienciam emoções negativas e um sentido de desorganização } \\
\text { perante a expressão emocional negativa da criança (Melo, 2005). Exemplos desta } \\
\text { amostra: ficar bravo. "até ameacei de morte o professor e um pai" (P5); "Na hora } \\
\text { fiquei brava" (M13). }\end{array}$ \\
\hline
\end{tabular}

com os filhos do sexo masculino, quando comparado às meninas $\left(\chi^{2}=3,90 ; p=0,048\right)$.

\section{História-Estímulo}

A quantificação das reações dos pais frente à raiva expressa pela criança a partir da história-estímulo, que versava sobre um conflito entre irmãos, ocorreu de forma semelhante ao item anterior, considerando os mesmos procedimentos e as mesmas categorias. Assim como nos outros itens, mais de uma categoria poderia ser utilizada para a mesma resposta, por exemplo: "desligaria a televisão pra entender o que estava acontecendo... né, pra resolver a situação se é questão de ficar na televisão vamos ficar se não vamos pensar pra eles se interterem com outras coisas" (M1) sendo as categorias reação centrada no problema e distração utilizadas nessa resposta.

Exemplos da presente amostra para cada categoria utilizada no estudo: A reação punitiva: colocar de castigo; mandar fazer a atividade que não quer; não deixar continuar assistindo/brincando, "dou um pito nos dois, quando acontece isso, corrijo os dois [...] e se isso voltar a acontecer, castigo para os dois" (P19). A categoria reação centrada no problema: conversar com eles; 
Tabela 4

Porcentagem e Número Absoluto quanto às Ocorrências e Quantidade de Pais para as Categorias Reações Parentais Frente à Raiva, conforme o Sexo do Filho

\begin{tabular}{|c|c|c|c|c|c|c|c|}
\hline \multirow{2}{*}{$\begin{array}{l}\text { Reações } \\
\text { parentais frente } \\
\text { à raiva }\end{array}$} & \multicolumn{2}{|c|}{$\mathrm{N}^{\mathrm{o}}$ de pais que falaram ${ }^{1}$} & \multicolumn{2}{|c|}{$\mathrm{N}^{\circ}$ de mães que falaram ${ }^{1}$} & \multirow{2}{*}{$\begin{array}{l}\text { Total de } \\
\text { ocorrência } \\
\text { pais }^{2}\end{array}$} & \multirow{2}{*}{$\begin{array}{l}\text { Total de } \\
\text { ocorrência } \\
\text { mães }^{2}\end{array}$} & \multirow{2}{*}{$\begin{array}{c}\chi^{2}(p) \text { [pais x } \\
\text { mães] }\end{array}$} \\
\hline & Filho & Filha & Filho & Filha & & & \\
\hline Distração & $0(0 \%)$ & $6(23,07 \%)$ & $2(7,69 \%)$ & $9(34,61 \%)$ & $6(9,52 \%)$ & $11(15,27 \%)$ & $1,76(0,185)$ \\
\hline $\begin{array}{l}\text { Reação centrada } \\
\text { no problema }\end{array}$ & $15(57,69 \%)$ & $14(53,84 \%)$ & $14(53,84 \%)$ & $15(57,69 \%)$ & $29(46,03 \%)$ & $29(40,27 \%)$ & $0,00(1,000)$ \\
\hline $\begin{array}{l}\text { Validação das } \\
\text { emoções }\end{array}$ & $0(0 \%)$ & $0(0 \%)$ & $0(0 \%)$ & $1(3,84 \%)$ & $0(0 \%)$ & $1(1,38 \%)$ & $1,01(0,315)$ \\
\hline $\begin{array}{l}\text { Reação } \\
\text { perturbada }\end{array}$ & $1(3,84 \%)$ & $1(3,84 \%)$ & $1(3,84 \%)$ & $0(0 \%)$ & $2(3,17 \%)$ & $1(1,38 \%)$ & $0,34(0,558)$ \\
\hline Reação punitiva & $7(26,92 \%)$ & $7(26,92 \%)$ & $8(30,76 \%)$ & $9(34,61 \%)$ & $14(22,22 \%)$ & $17(23,61 \%)$ & $1,15(0,284)$ \\
\hline $\begin{array}{l}\text { Reação de } \\
\text { minimização }\end{array}$ & $9(34,61 \%)$ & $3(11,53 \%)$ & $9(34,61 \%)$ & $4(15,38 \%)$ & $12(19,04 \%)$ & $13(18,05 \%)$ & $0,05(0,819)$ \\
\hline Total & 32 & 31 & 34 & 38 & 63 & 72 & \\
\hline
\end{tabular}

Nota. 1) Cada pai/mãe pode ter apresentado respostas classificadas em mais de uma categoria; 2) Cada pai/mãe pode ter apresentado mais de uma resposta classificada na mesma categoria ao longo da entrevista.

delimitar horário para cada um; "têm que tentar ouvir os dois lados mais tirando o que foi lá incomodar na realidade, tirando dali o que foi perturbar" (M5).

Exemplos da presente amostra para a categoria distração: falar para pensar em outra atividade; mandar fazer a tarefa, "procuro fazer com que eles se entendam, mas às vezes tem que intervir e tirar de perto, 'não, vem aqui me ajudar à mamãe', já chamo, tiro um" (M16). Para a reação perturbada: ameaçar que irá bater, “[...] já desligo ali e daí às vezes eu pego a cinta, eu não bato, mas eu pego" (M24). Quanto à reação de minimização: mandar um dos filhos ceder ao desejo do outro, minimizar a magnitude da emoção vivenciada: "Tentando conscientizar o mais velho, que o mais novo não entende, pra deixar ele assistir o desenho, depois ele assiste." (M14); “chamo a atenção dela que não adianta ela chorar que ela não vai convencer” (M23).

Verificou-se que quando a raiva é desencadeada a partir de uma situação envolvendo conflito entre os irmãos, a estratégia mais frequentemente empregada pelo pai e pela mãe foi reação punitiva, seguida por reação centrada no problema. Ao se comparar o total de respostas de pai e mãe, constatou-se que as mães tendem a usar a estratégia de minimização com maior frequência, quando comparadas aos pais $\left(\chi^{2}=3,83\right.$; $p=0,050)$ (Tabela 5). Verificou-se ainda a existência de diferença estatisticamente significativa na reação de mães e pais em relação a filhos e filhas. Observou-se que $69,23 \%$ das mães utilizaram-se da categoria reação centrada no problema com as filhas e apenas 38,46\% empregaram essa estratégia de RE com os filhos, sendo essa diferença estatisticamente significativa $\left(\chi^{2}=4,95 ; p\right.$ $=0,026)$. Quanto à categoria minimização, novamente foi utilizada pelas mães mais frequentemente para as filhas do que para os filhos $\left(\chi^{2}=7,58 ; p=0,006\right)$.

\section{Discussão}

\section{Eliciadores da Raiva nas Crianças}

Os principais eliciadores de raiva nos filhos, na percepção dos pais da presente pesquisa, envolvem situações de frustração e conflito entre pares/irmãos. Contudo, na percepção das crianças, os eliciadores da raiva, mais frequentes estão relacionados a agressão verbal ou física (Cruvinel, 2009; Reis, 2014), sendo que essa foi à terceira categoria, em termos de frequência, citada pelos pais deste estudo. No estudo de Ferrari et al. (manuscrito submetido para publicação) que investigou os eliciadores da raiva na percepção das mães a categoria brigas com amigos e irmãos foram elencados como os principais motivos que geram essa emoção negativa nas crianças. Acredita-se que os pais tendem a identificar mais facilmente esta nos filhos quando estão em uma interação direta, assim a frustração na 
Tabela 5

Ocorrências e Número de Pais que Relataram sobre as Categorias de Reações Parentais frente à Raiva na História Estímulo

\begin{tabular}{|c|c|c|c|c|c|c|c|}
\hline \multirow{2}{*}{$\begin{array}{l}\text { Reações } \\
\text { parentais frente } \\
\text { à raiva }\end{array}$} & \multicolumn{2}{|c|}{$\mathrm{N}^{o}$ de pais que falaram ${ }^{1}$} & \multicolumn{2}{|c|}{$\mathrm{N}^{\mathrm{o}}$ de mães que falaram ${ }^{1}$} & \multirow{2}{*}{$\begin{array}{l}\text { Total de } \\
\text { ocorrência } \\
\text { pais }^{2}\end{array}$} & \multirow{2}{*}{$\begin{array}{l}\text { Total de } \\
\text { ocorrência } \\
\text { mães }^{2}\end{array}$} & \multirow{2}{*}{$\begin{array}{c}\chi^{2}(p)[\text { pais x } \\
\text { mães] }\end{array}$} \\
\hline & Filho & Filha & Filho & Filha & & & \\
\hline Distração & $3(11,53 \%)$ & $5(19,23 \%)$ & $3(11,53 \%)$ & $12(46,15 \%)$ & $8(10,25 \%)$ & $15(16,66 \%)$ & $2,74(0,098)$ \\
\hline $\begin{array}{l}\text { Reação centrada } \\
\text { no problema }\end{array}$ & $15(57,69 \%)$ & $17(65,38 \%)$ & $10(38,46 \%)$ & $18(69,23 \%)$ & $32(41,02 \%)$ & $28(31,11 \%)$ & $0,63(0,427)$ \\
\hline $\begin{array}{l}\text { Reação } \\
\text { perturbada }\end{array}$ & $2(7,69 \%)$ & $0(0 \%)$ & $2(7,69 \%)$ & $1(3,84 \%)$ & $2(2,56 \%)$ & $3(3,33 \%)$ & $0,21(0,647)$ \\
\hline Reação punitiva & $19(73,07 \%)$ & $17(65,38 \%)$ & $18(69,23 \%)$ & $19(73,07 \%)$ & $36(46,15 \%)$ & $37(41,11 \%)$ & $0,05(0,830)$ \\
\hline $\begin{array}{l}\text { Reação de } \\
\text { minimização }\end{array}$ & $0(0 \%)$ & $1(3,84 \%)$ & $4(15,38 \%)$ & $2(7,68 \%)$ & $1(1,28 \%)$ & $6(6,66 \%)$ & $3,83(0,050)$ \\
\hline Total & 39 & 40 & 37 & 52 & 79 & 89 & \\
\hline
\end{tabular}

Nota. 1) Cada pai/mãe pode ter apresentado respostas classificadas em mais de uma categoria; 2) Cada pai/mãe pode ter apresentado mais de uma resposta classificada na mesma categoria ao longo da entrevista; 3) Células em negrito indicam testes qui-quadrado que demonstraram diferenças estatisticamente significativas $(\phi \leq 0,05)$ entre pais e mães.

criança foi gerada pelos próprios pais, ou eles estavam presentes na situação. Este é pertinente quanto a brigas entre os irmãos, uma vez que geralmente cabe aos pais a resolução de tais conflitos. No entanto, episódios de agressão física e verbal sofridos pelos pares nem sempre são presenciados pelos pais ou relatados a eles pelos filhos, o que pode fazer com que tais eventos passem despercebidos aos cuidadores.

Essa hipótese parece ser corroborada pelos resultados de Ribas et al. (2006) que verificaram que 55\% dos pais que possuem estresse em seu cotidiano relatam não terem tempo para si, provavelmente devido ao tempo destinado ao trabalho, e também pela fala de um dos pais: "a A. ajuda nas tarefas [...] e eu já não estou em casa" (P3). Ao considerar que a raiva é uma emoção básica presente em todos os indivíduos, é razoável supor uma falta de diálogo e conhecimento dos pais em relação às vivências emocionais em relação ao mundo dos filhos. Isso parece se confirmar ainda pelo fato de que os pais desta pesquisa relataram com mais frequência do que as mães não saber sobre o que gera raiva nos filhos. Estes dados corroboram com o estudo de Dias (2015), que verificou que a figura paterna fria, distante e que priva o filho de afeto, pode acarretar em adultos com elevados níveis de raiva, sendo importante observar tal dado para compreender os estilos parentais dos adultos, entendendo o grau de consequência que esta vinculação seja proveniente da infância.
Não houve diferenças levando-se em conta o total de respostas, independente do sexo da criança, na percepção de pais e mães quanto a considerar a falta de suporte afetivo-social como apostrofador da raiva, porém verificou-se que as mães identificaram que tal estímulo gera esta emoção negativa com maior frequência nas meninas, quando comparadas aos meninos. Presume-se que, na percepção das mães, falta de suporte afetivo causa vulnerabilidade às meninas a sentirem raiva, mas não aos meninos. Baptista, Carneiro e Sisto (2010) postulam que as crianças de pais com maior instrução possuem maior discriminação de estados afetivos, maior comunicação e sentimento de pertença, propiciando um ambiente para o desenvolvimento cognitivo e social. Dessa forma, verifica-se a importância de observar os comportamentos das crianças bem como as reações parentais a fim de evitar falta de suporte afetivo-social como eliciador de raiva nas crianças. Bem como o estudo de Dias (2015), o qual verificou que quanto melhor é a qualidade do laço emocional estabelecido entre pais e mães com seus filhos, de forma mais adequada os filhos tem a capacidade de expressar a raiva.

\section{Reações Parentais frente à Situação Especifica}

Os resultados da presente pesquisa indicam que a estratégia de RE mais empregada por pais e mães frente à raiva dos filhos foi a reação centrada no problema. De 
acordo com Alves e Cruz (2011), mães com maior nível de escolaridade apresentaram mais reações centradas no problema. Na presente amostra, obteve-se um bom índice de escolaridade de pais e mães, com uma média de aproximadamente 13 anos de estudo, o que corrobora os achados dos referidos autores. Por sua vez, Fabes, Eisenberg e Bernzweig (1990) e Pinheiro (2015), propuseram que respostas parentais centradas na emoção e no problema estão associadas ao maior controle da atenção, reações de encorajamento da expressividade, melhor funcionamento social e a estratégias de enfrentamento construtivas por parte das crianças. $\mathrm{O}$ que mostra que os pais e mães da presente pesquisa exprimem reações adaptativas frente à raiva dos filhos e que a variável escolaridade pode moderar essa relação.

No entanto, embora relatadas com menor frequência, foram também bastante citadas as estratégias de punição e minimização. Chang et al. (2003) encontraram que o pai com parentalidade severa afeta os filhos do sexo masculino mais do que as meninas, enquanto que não houve efeito diferencial em relação ao sexo com mães de parentalidade severa. Na presente amostra, os resultados encontrados para os pais e mães, referem que estes, usam igualmente a reação punitiva para ambos os filhos, o que ilustra a necessidade de intervenção de modo a conscientizar os pais de que tais ações são negativas e nocivas à RE emocional infantil.

Ao se comparar a maneira com a qual pais e mães lidam com a raiva de meninos e meninas, constatou-se que a distração foi significativamente mais empregada para as filhas por ambos os cuidadores e que minimização foi mais citada para os meninos. Alves e Cruz (2011) verificaram que mães de meninos apresentaram mais frequentemente reações de punição e aborrecimento frente à raiva dos filhos, quando comparadas às mães de meninas. Embora este resultado não tenha se replicado na presente pesquisa, supõe-se que, na percepção dos pais, distração seja algo positivo, uma vez que arrefece a intensidade da emoção em curso em um espaço de tempo relativamente curto. Por outro lado, a minimização diminui a importância da emoção ou do problema que a ocasionou, o que mostra que os cuidadores tendem a ser menos atenciosos frente ao emocional dos filhos do sexo masculino. Assim, visualiza-se na presente amostra, uma diferença na parentalidade conforme o sexo da criança.

\section{Reações Parentais frente à História-Estímulo}

Frente à história-estímulo que versava sobre uma situação de conflito entre irmãos, pai e mãe utilizaram com mais frequência a reação punitiva para filho e filha. No entanto, no estudo de Sampaio e Vieira (2010) meninas foram tratadas de modo diferente pelo pai, sofrendo mais com as práticas negativas, quando comparadas aos meninos e as meninas têm modelo de comportamento moral mais alto por parte das mães, e os meninos são mais monitorados positivamente por parte do pai. De acordo com Ribas et al. (2006) há grande importância do bem-estar parental para que práticas educativas positivas possam ser colocadas em prática, principalmente no que tange à modelação de estratégias adaptativas de RE. Considerando que muitos pais passam o dia trabalhando e pouco tempo com os filhos, soma-se o cansaço e situações de conflito entre os irmãos, por exemplo, de forma que se utilizam da punição para cessar o problema, colocando de castigo, por exemplo, sem exigir maior tempo e disponibilidade para conversa dos genitores.

A reação centrada no problema foi a segunda mais relatada pelos genitores frente à história-estímulo, sendo que o pai a emprega uniformemente entre os filhos e a mãe a utiliza mais para meninas do que para os meninos. Acredita-se que cabe às mães a resolução de conflitos entre os filhos e, corroborando os resultados de Sampaio e Vieira (2010), é possível que exista a identificação sexual da mãe em relação à filha.

Observa-se que a mãe utilizou a reação de minimização para ambos os filhos e que apenas um pai referiu usar essa estratégia em relação à filha. Sugere-se que os pais se utilizam menos da minimização, pois permanecem pouco tempo com os filhos. Conforme Wagner, Predebon, Mosmann e Verza (2005) os pais tem maior nível de escolaridade e melhores condições econômicas, porém passam menos horas com os filhos do que as mães. Contudo, não foram encontrados estudos que fazem diferenciação entre meninos e meninas em relação à minimização.

Os pais e mães neste estudo não validam a raiva dos filhos independentemente do sexo. De forma semelhante, no estudo de Lourenço, Palmeira, Dinis e Gouveia (2010) que investigaram a percepção dos filhos acerca da reação das mães frente às emoções negativas expressas por elas. Sendo que as mães se utilizam da punição, contribuindo para desencadear sentimentos de vergonha bem como sintomas depressivos e ansiosos. Portanto, verifica-se a importância da prática parental em relação à validação emocional.

\section{Considerações Finais}

Em relação aos eliciadores da raiva conclui-se que os mais presentes no cotidiano das crianças de 6 a 12 
anos, na percepção de pais e mães, são a frustração e o conflito entre pares/irmãos. Uma diferença foi encontrada em relação às mães com as filhas do sexo feminino, pois as progenitoras acreditam que falta de suporte afetivo-social desencadeia esta emoção negativa nas meninas, mas não nos meninos. Os pais e as mães, quando comparados entre si, utilizam-se das mesmas estratégias frente à expressão de raiva dos filhos de ambos os sexos, sendo as mais utilizadas a reação centrada no problema e a reação punitiva, respectivamente estratégias, adaptativa e desadaptativa. No entanto, pai e mãe tenderam a apresentar a reação de minimização mais frequentemente com o filho e a reação de distração mais frequentemente com a filha. Verificando-se, neste estudo, algumas diferenças de gênero quanto à prática parental.

Quando os pais atendem às necessidades da criança, a auxiliando na regulação de suas emoções, além de proporcionar-lhe um senso de segurança, esta tende a utilizar estratégias semelhantes àquelas empregadas pelos pais, o que permitirá o desenvolvimento de competências de RE (Rei, 2012), portanto ressalta-se a importância de treinamentos para pais com a finalidade de priorizar as formas de relacionamento entre pais e filhos.

Apesar do contributo do presente estudo, existem algumas limitações. Uma delas prende-se com o tamanho reduzido da amostra. Pois à definição dos participantes com características específicas tornou o universo da pesquisa limitada. Pôde-se verificar que metade dos contatos realizados não aceitou participar do estudo, o que torna a amostra menor. Outra limitação seria questionar aos pais os motivos pelos quais adotam as estratégias citadas, na tentativa de entender um pouco da vivência familiar e qual a percepção dos pais sobre suas reações. Esses dados poderiam enriquecer o trabalho e tentar compreender, da melhor forma, a percepção dos pais.

Sugerem-se novas pesquisas em que se avaliem práticas parentais frente aos filhos relacionadas à carga horária e demanda de trabalho de pais e mães. Como também, investigar as práticas parentais de RE comparando o grupo de pais e mães com ambiente familiar positivo e negativo, bem como variáveis moderadoras (ou seja, pais que tiveram um ambiente hostil na infância, mas desenvolveram práticas positivas).

\section{Referências}

Alves, D., \& Cruz, O. (2011). Reacções parentais às emoções negativas dos filhos (Rpen):
Um questionário de avaliação da meta-emoção parental. Em VIII Congresso Iberoamericano de Avaliação/Evaluación Psicológica e XV Conferência Internacional Avaliação Psicológica: Formas e Contextos. Recuperado de http://repositorio-aberto.up.pt/ handle/10216/57244.

Associação Brasileira de Empresas de Pesquisa. (2013). Critério de Classificação Econômica Brasil. Recuperado de http://www.abep.org/new/criterioBrasil.aspx.

Baptista, M. N., Carneiro, A. M., \& Sisto, F. F. (2010). Estudo psicométrico de escalas de depressão (EDEP e BDI) e o Inventário de Percepção de Suporte Familiar (IPSF). Psicologia em Pesquisa, 4(1), 65-73. Recuperado de http:/ /www.ufjf.br/psicologiaempesquisa/files/2010/07/v4n1a09.pdf

Canavarro, M. C., \& Pereira, A. I. (2007). A percepção dos filhos sobre os estilos educativos parentais: A versão portuguesa do EMBU-C. RIDEP, 24(2) 193-210. Recuperado de http://www.aidep. org/03_ridep/R24/R2410res.pdf

Carmo, P. H. B., \& Alvarenga, P. (2012). Práticas educativas coercitivas de mães de diferentes níveis socioeconômicos. Estudos de Psicologia, 17(2), 191197. Recuperado de http://www.scielo.br/pdf/ epsic/v17n2/01.pdf

Chang, L., Schwartz, D., Dodge, K. A., \& McBride-Chang, C. (2003). Harsh parenting in relation to child emotion regulation and aggression. Journal of Family Psychology, 17(4), 598-606. doi: 10.1037/0893-3200.17.4.598

Cole, P. M., Martins, S. E., \& Dennis, T. A. (2004). Emotion regulation as a scientific construct: Methodological challenges and directions for child development research. Child Development, 75(2), 317-333. Recuperado de http://www.psy.miami. edu/faculty/dmessinger/c_c/rsrcs/rdgs/emot/ coleetal2004.pdf

Crespo, L. M. (2013). Parent-Child emotion talk in relation to parental socialization and emotion regulation: The role of parent and child gender (Artigo de bacharelado não publicado). Collegeof William \& Mary. Recuperado de https://dspace.swem.wm.edu/ handle/10288/18428.

Cruvinel, M. (2009). Correlatos cognitivos e psicossociais de criancascomesem sintomas depressivos(Tese de doutorado não publicada). Universidade Estadual de Campinas. 
Recuperado de http://www.bibliotecadigital.unicamp.br/document $/$ ?code $=000446385 \& f d=y$

Cruvinel, M., \& Boruchovich, E. (2010). Regulação emocional: A construção de um instrumento e resultados iniciais. Psicologia em Estudo, 15(3), 537-545. doi: 10.1590/S1413-73722010000300011

Dias, C. S. B. M. R. (2015) A raiva: Relações com a vinculação e com os estilos parentais percebidos (Dissertação de mestrado integrado em Psicologia), Universidade de Lisboa. Recuperado de https://repositorio. ul.pt/handle/10451/23018.

Dias, M. G. B. B., Santos, L. B., \& Roazzi, M. (2006). Cognição e emoção: Pressupostos, teorias e estudos empíricos. Em L. L. Meira \& A. G. Spinillo. (Eds.), Psicologia cognitiva: cultura, desenvolvimento e aprendizagem (122-146). Recife: Universitária EFPE.

Diefenbach, M. A., Miller, S. M., Porter, M., Peters, E., Stefanek, M., \& Leventhal, H. (2008). Emotions and health behavior: A self-regulation perspective. Em M. Lewis, J. M. Haviland-Jones \& L. F. Barrett (Eds.), Handbook of emotions. (645-660). New York: The Guilford Press. Recuperado de http:// boccignone.di.unimi.it/CompAff2014_files/ Handbook-of-Emotions.pdf

Fabes, R. A., Eisenberg, N., \& Bernzweig, J. (1990). The Coping with Children's Negative Emotions Scale: Procedures and scoring. Available from authors. Arizona State University.

Eisenberg, N., \& Spinrad, T. L. (2004). Emotion-related regulation: Sharpening the definition. Child Development, 75(2), 334-339. Recuperado de http://www. jstor.org $/$ discover $/ 10.2307 / 3696639$ ?uid $=2 \& u i d$ $=4 \& \operatorname{sid}=21103751434297$

Ekman, P. (1999). Basic emotions. In T. Dalgleish \& M. Power (Eds.). Handbook of cognition and emotion. Sussex, U. K.: John Wiley \& Sons. Recuperado de http://www.paulekman.com/wp-content/ uploads/2013/07/Basic-Emotions.pdf.

Reis, A. H., Ferrari, L. B, \& Sperb, T. M. (2016). Reação materna frente à expressão emocional de raiva e tristeza dos filhos. Revista Brasileira de Terapia Comportamental e Cognitiva, XVIII(2), 20-34. Recuperado de http://www.usp.br/rbtcc/index.php/RBTCC/ article/view/881/477

Graziano, P. A., Reavis, R. D., Keane, S. P., \& Calkins, S. P. (2007). The role of emotion regulation in children's early academic success. Journal of School Psychology, 453-19. doi: 10.1016/j.jsp.2006.09.002

Leahy, R. L., Tirch, D., \& Napolitano, L. A. (2013). Regulação emocional em psicoterapia: Um guia para o terapeuta cognitivo-comportamental. Porto Alegre: Artmed.

Lemerise, E. A., \& Dodge, K. A. (2008). The development of anger and hostile interactions. Em M. Lewis, J. M. Haviland-Jones, \& L. F. Barrett (Eds.), Handbook of emotions. (730-741). New York: The Guilford Press. Recuperado de http://boccignone. di.unimi.it/CompAff2014_files/Handbook-ofEmotions.pdf

Lipp, M. N. (2005). Stress e o turbilhão da raiva. São Paulo: Casa do Psicólogo.

Lourenço, S., Palmeira, L., Dinis, A., \& Gouveia, J. P. (2010). Validação das emoções na infância: Vergonha, ansiedade e sintomatologia depressiva. Psychologica, 2 (52). Recuperado de http://193.136.6.118/jspui/handle/10316.2/3482

Macedo, L. S. R. d., \& Sperb, T. M. (2013). Regulação de emoções na pré-adolescência e influência da conversação familiar. Psicologia: Teoria e Prática, 29(2), 133-140. Recuperado de https://revistaptp.unb. br/index.php/ptp/article/view/841

Ortony, A., \& Turner, T. J. (1990). What's basic about basic emotions? Psychological Review, 97(3), 315331. Recuperado de http://www.cs.northwestern. edu/ ortony/Andrew_Ortony_files/Basic_ Emotions.pdf

Palmeira, L., Gouveia, J. P., Dinis, A., \& LourençO, S. (2011). O papel dos esquemas emocionais na transgeracionalidade do processo de socialização das emoções negativas. Psycolhogica, 54, 439-464. Recuperado de http://98.130.112.242/index.php/ psychologica/article/view/1115

Phillips, L. H., Henry, J. D., Hosie, J. A., \& Milne, A. B. (2006). Age, anger regulation and well-being. Aging \& Mental Health, 10(3), 250-256. doi: 10.1080/13607860500310385

Pinheiro, M. A. F. M. (2015) Parentalidade, adaptação e temperamento da criança: Estudo com uma amostra clínica de crianças em idade escolar (Dissertação de mestrado integrado em Psicologia). Universidade de Lisboa. Recuperado de http://repositorio.ul.pt/ handle/10451/23067 
Rei, S. L. (2012). Sou o que sinto!: A relação entre a regulação emocional e o ajustamento psicológico em crianças e jovens (Dissertação de mestrado não publicada da Secção de Psicologia Clínica e da Saúde - Núcleo de Psicoterapia Cognitiva, Comportamental e Integrativa). Universidade de Lisboa. Recuperado de http://repositorio.ul.pt/handle/10451/8058.

Reis, A. H. (2014). Desenvolvimento de uma intervenção para a raiva em crianças e validação da escala Emotion Regulation Checklist (Tese de doutorado não publicada). Universidade Federal do Rio Grande do Sul.

Ribas, A. F. P., Ribas Junior, R. d. C., \& Valente, A. A. (2006). Bem-estar emocional de mães e pais e o exercício do papel parental: Uma investigação empírica. Revista brasileira de crescimento e desenvolvimento bumano, 16, 28-38. Recuperado de http://www.revistas.usp.br/jhgd/article/viewFile/19800/21870

Sampaio, I. T. A., \& Vieira, M. L. (2010). A influência do gênero e ordem de nascimento sobre as práticas educativas parentais. Psicologia: Reflexão e Crítica, (23), 198-207, doi: 10.1590/S0102-79722010000200002

Szasz, P. L., Szentagotai, A., \& Hofmann, S. G. (2011). The effect of emotion regulation strategies on anger. Behaviour Research and Therapy, 49, 114-119. doi: 10.1016/j.brat.2010.11.011
Ventura, M. M. (2007). O estudo de caso como modalidade de pesquisa. Revista SoCERJ, 20(5), 383-386. Recuperado de http://www.polo.unisc.br/portal/ upload/com_arquivo/o_estudo_de_caso_como_ modalidade_de_pesquisa.pdf

Wagner, A., Predebon, J., Mosmann, C., \& Verza F. (2005). Compartilhar Tarefas? Papéis e funções de pai e mãe na família contemporânea. Psicologia: Teoria e Pesquisa, 21(2), 181-186. doi: 10.1590/ S0102-37722005000200008

Waters, S. F., \& Thompson, R. A. (2014). Children's perceptions of the effectiveness of strategies for regulating anger and sadness. International Journal of Behavior Development, 1-8. doi: 10.1177/0165025413515410

Widen, S. C., \& Russell, J. A. (2008). Young children's understanding of others' emotions. Em M. Lewis, J. M. Haviland-Jones \& L. F. Barrett (Eds.), Handbook of emotions. (348-363). New York: The Guilford Press. Recuperado de http:/ / boccignone. di.unimi.it/CompAff2014_files/Handbook-ofEmotions.pdf

Recebido em: 10/12/2015

Reformulado em: 21/10/2016

Aprovado em: 13/03/2017 
Sobre as autoras:

Bruna Patrycia Waligura de Oliveira é graduada em Psicologia pela Faculdade Assis Gurgacz, especialista em Gestão de Recursos Humanos pelo Centro Universitário de Cascavel - Univel e atua como psicóloga organizacional na Nutriplan.

E-mail: brunapwoliveira@gmail.com

Ana Karoline Gomes Gurtat é graduada em Psicologia pela Faculdade Assis Gurgacz, especialista em Terapia Analítico Comportamental pela Universidade Paranaense e atua como psicóloga clínica na Psi Clínica e no Centro de reabilitação do Centro Universitário FAG e no setor de Recursos Humanos.

E-mail: anakarolineggurtat@hotmail.com

Alice Henriques Reis é doutora em Psicologia pela Universidade Federal do Rio Grande do Sul, especialista em Psicologia Clínica na Abordagem Cognitivo-Comportamental pela Universidade Federal de Uberlândia/MG, com formação em Terapia do Esquema pela Wainer e Piccoloto Centro de Psicoterapia, professora adjunta do curso de Psicologia da Universidade Federal de Mato Grosso do Sul e terapeuta Cognitiva Certificada pela Federação Brasileira de Terapias Cognitivas.

E-mail: alinehreis@gmail.com

\section{Contato com as autoras:}

Universidade Federal de Mato Grosso do Sul. Faculdade de Ciências Humanas (FACH), curso de Psicologia.

Av. Costa e Silva, s/nº, Bairro Universitário

CEP: 79070-900

Campo Grande-MS, Brasil 


\section{ERRATA 1}

No artigo "Manejo dos Pais Frente à Expressão de Raiva dos Filhos", com número de DOI: 10.1590/141382712018230208, publicado no periódico Psico-USF, 23(2): 279-293, nas páginas 279 e 293:

Onde se lia: "Alice Henriques Reis"

Leia-se: "Aline Henriques Reis" 